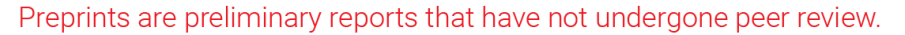 They should not be considered conclusive, used to inform clinical practice, or referenced by the media as validated information. \\ Quantitative Analysis of Eco-Economic Benefit of Urban Reclaimed Water Greening Based on Emergy Theory
}

\section{Cuimei Lv}

Zhengzhou University

\section{Yifan He}

Zhengzhou University

\section{Wenge Zhang ( $\square$ zhangwenge@yeah.net) \\ Yellow River Conservancy Commission}

\section{Changkuan Gu}

Kaifeng Hydrology and Water Resources Survey Bureau of Henan Province

\section{Yang Li}

Kaifeng Hydrology and Water Resources Survey Bureau of Henan Province

\section{Denghua Yan}

China Institute of Water Resources and Hydropower Research

\section{Research Article}

Keywords: Emergy method, Reclaimed water reuse, Urban green irrigation, Composition of eco-economic benefits, Zhengzhou city

Posted Date: July 21 st, 2021

DOl: https://doi.org/10.21203/rs.3.rs-626789/v1

License: (c) (i) This work is licensed under a Creative Commons Attribution 4.0 International License. Read Full License 


\section{Quantitative Analysis of Eco-economic Benefit of Urban}

\section{Reclaimed Water Greening Based on Emergy Theory}

Cuimei $\mathrm{Lv}^{\mathrm{a}}$, Yifan $\mathrm{He}^{\mathrm{a}}$, Wenge Zhang ${ }^{\mathrm{b}}$, , Changkuan $\mathrm{Gu}^{\mathrm{c}}$, Yang $\mathrm{Li}^{\mathrm{c}}$, Denghua Yan $^{\mathrm{d}}$

${ }^{a}$ School of Water Conservancy Engineering, Zhengzhou University, Zhengzhou, Henan 450001, PR China

${ }^{b}$ Yellow River Institute of Hydraulic Research, Yellow River Conservancy

Commission, Zhengzhou Henan 450003, PR China

${ }^{c}$ Kaifeng Hydrology and Water Resources Survey Bureau of Henan Province,

Kaifeng, Henan 475000, PR China

${ }^{d}$ Water Resources Department, China Institute of Water Resources and Hydropower Research, Beijing 100038, PR China

lvcuimei305@163.com（C.Lv); h3938596372@gs.zzu.edu.cn（Y.He); zhangwenge@yeah.net（W.Zhang); $\quad 3262689802 @ q q . c o m \quad$ (C.Gu); f15036102300@163.com (Y.Li); ydhzzu@126.com (D.Yan).

${ }^{*}$ Corresponding author: zhangwenge@yeah.net (W.Zhang)

Present/permanent address:

No. 45 Shunhe Road, Jinshui District, Zhengzhou City, Henan Province, China, 450003, PR China

* Corresponding author.

E-mail address: zhangwenge@yeah.net (W. Zhang). 
Abstract: With the faster urbanization and the higher living environment requirements of people, the urban green area is getting increasingly attention. But green irrigation consumes huge tap water, causes the waste of high-quality water resources. The reclaimed water meets the standard of green irrigation and the source is sufficient, it is a good alternative water source for urban greening. The eco-economic benefit of using reclaimed water as greening water was evaluated in this paper. The composition of benefit was analyzed and the difference in benefit brought by using reclaimed water greening instead of tap water was quantified based on emergy theory. Taking Zhengzhou in 2018 for example, the results showed that the eco-economic benefit of reclaimed water greening was remarkable. The total eco-economic benefit was $\$ 4.05$ billion, which was three times of that of tap water. Among the benefits, economic benefit accounted for the largest proportion, reaching 69.22\%. After deducting the cost, the net eco-economic benefit of reclaimed water greening was $\$ 2.00$ billion, while tap water was negative. Therefore, using reclaimed water to irrigate urban green area can save a lot of high-quality water and bring a lot of economic, social and ecological environmental benefits. The quantitative results of this paper can provide reference for the promotion of reclaimed water greening and the allocation decision of reclaimed water in water shortage areas. And it is helpful to improve the utilization efficiency of water resources and alleviate the shortage of urban water resources.

Key words: Emergy method, Reclaimed water reuse, Urban green irrigation, Composition of eco-economic benefits, Zhengzhou city 


\section{Introduction}

Urban green area can not only purify the air, clean the environment, but also beautify the city, meet people's needs for the environment and provide a place for spiritual rest. In recent years, cities in various countries have attached great importance to greening the environment. Such as Warsaw has the largest forest coverage in the world, the per capita green area is $78 \mathrm{~m}^{2}$, which in Moscow is $44 \mathrm{~m}^{2}$, in Paris is $25 \mathrm{~m}^{2}$, and in Beijing is only $16.3 \mathrm{~m}^{2}$. Compared to the international green cities, China's urban greening construction still needs to be strengthened. In recent years, China has begun to improve the greening construction, and the urban greening coverage rate has increased from $28.2 \%$ in 2001 to $40 \%$ in 2018 . With the rapid development of greening construction, a large amount of water resources consumed by greening irrigation has also become one of the important factors to aggravate the shortage of water resources.

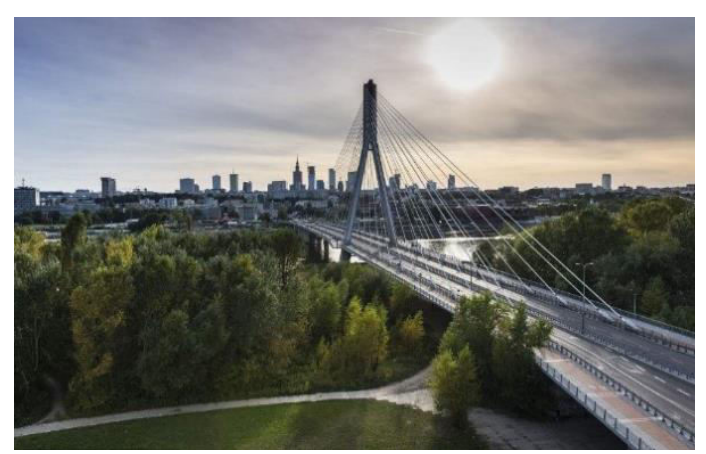

Fig1 Urban greening in Warsaw

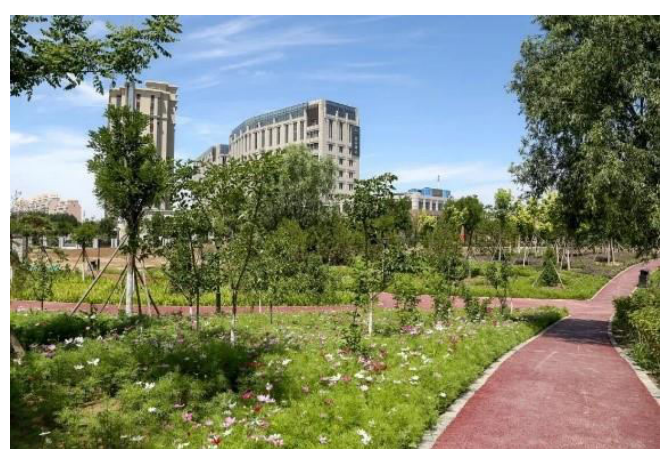

Fig2 Urban greening in Beijing

Reclaimed water reuse as a substitute for high quality water source, has become one of the most important approaches to solve the water crisis. The reclaimed water meets the requirements of urban greening irrigation in terms of water quality, ion content and other indexes, and will not cause harm to the green space ecosystem 
(Wang 2010) and human health (Wang et al. 2012). Therefore, reclaimed water can replace the role of tap water in urban greening. Greening with reclaimed water creates the same social and ecological benefits as tap water, while also saves quality water and brings additional economic benefits. Recognizing and analyzing the benefits of reclaimed water greening is helpful to its wider using, and provides a reference for the reasonable distribution of reclaimed water.

Research on the benefits of reuse of reclaimed water, as early as 2005, Tsagarakis (2005) discussed the economic benefit of wastewater reuse in the context of the 2000/60/EC Water Framework Directive. He stressed the need for practical work on the assessment of the costs and benefit of water reuse. After this, lots of scholars focused on the economic benefit of reclaimed water (Birol et al. 2010; Alcon et al. 2012; Chen \& Gan 2014), and some scholars studied the ecological and environmental benefit (Giannoccaro et al. 2019; Cirelli et al. 2007; Li 2017).

In terms of quantifying the benefit of reclaimed water reuse, most scholars adopted economic methods. Such as Alcon et al. (2013) evaluated the feasibility of reclaimed water utilization in agriculture through cost-benefit analysis. Pérez-Pérez et al. $(2010,2014)$ also used cost-effectiveness to quantify the benefits of water reuse. Maestre-Valero et al. (2016) used the discounted cash flow method to calculate the profitability of reclaimed water and tap water irrigation. But these methods are in economics perspective, without linking ecology and economics, and cannot reflect the natural properties of water resources, so it is hard to accurately measure the true benefits of water resources ( $\mathrm{Lv} 2009)$. The traditional economic approach, is from 
the monetary theory derived from human society, establishing ecological values on human preferences, which difficult to evaluate the value of natural resource systems (Lan et al. 2002). While the burgeoning eco-economic emergy theory unifies energy flow, material flow and monetary flow for quantitative analysis, providing a mutually commutative metric between economics and ecology to achieve the objective and unified quantification of eco-economic value. In this paper, the emergy theory of ecological economics is used to comprehensively analyze the composition of ecological and economic benefits of reclaimed water greening, and a scientific benefits quantification method was given. Provide new ideas for quantitative analysis of benefits of reclaimed water reuse and its rational distribution and utilization.

\section{Materials and Methods}

\subsection{Emergy theory}

Emergy theory and analysis method was founded by famous American ecologist H.T.Odum (Odum 1996; Brown \&Ulgiati et al. 2004) . Emergy theory is based on the viewpoint of energy flow, taking solar energy as the standard. Through emergy theory, different substances and energy were changed to solar energy to realize the objective and unified quantification of eco-economic benefit. Emergy theory is the bridge between ecology and economics. The formula of emergy is:

$$
E M=\tau B
$$

Where $E M$ is the solar emergy (sej), $\tau$ is the transformity (sej $\mathrm{J}^{-1}$ or sej $\mathrm{g}^{-1}$ ), $B$ is the energy or quantity of substances ( $\mathrm{J}$ or g). 
According to the emergy analysis method, the relationship between solar energy value and traditional currency can be established by emergy currency ratio. The total emergy value used by a country or region in the whole year divided by the gross national product of the country or region, which could get the emergy currency ratio. Through the emergy currency ratio, the emergy benefits of eco-economic system can be converted into monetary benefits, the formula is:

$$
E M \$=E M \div E D R
$$

Where $E M \$$ is the monetary value equivalent to emergy value $(\$), E D R$ is the emergy currency ratio $\left(\right.$ sej $\left.\$^{-1}\right)$.

Emergy theory is not a substitute for money to measure economic behavior, but a theory to make up for and improve the shortcomings of traditional economic methods. Some scholars (Wu et al. 2017; Lv et al. 2019) applied the emergy theory to the ecological-economic evaluation of water resource system and achieved rich results. In this study, the emergy theory of ecological economics was used to fully consider the benefits of using reclaimed water instead of tap water to irrigate urban green space. And the emergy quantitative method of economic, social and ecological environment benefit was established.

\subsection{Composition of Eco-economic benefit of reclaimed water}

\section{greening}

The growth of urban green vegetation is inseparable from the irrigation of water resource. Water is not only an important part of plants, but also plays an important role in the process of material transportation and metabolism. So, the eco-economic 
benefit brought by reclaimed water greening not only consist of economic benefit formed by replacing tap water sources with reclaimed water, but also include social benefit and eco-economic benefit formed by the ecological service function of urban green itself.

(1) The economic benefit mainly includes two aspects. On the one hand, the different processes of water intaking, purification, disinfection and transportation between tap water and reclaimed water will bring cost difference. On the other hand, if the saved tap water from reclaimed water greening was applied to urban life and industry, it could generate economic benefit.

(2) Social benefits include scientific research, leisure and entertainment. Reclaimed water greening encourages more savants to conduct scientific research and publish related papers for in-depth research, serve humanity better. Urban parks and green plants can reduce dust and noise, provide a beautiful living environment, and delight the mood of urban residents. The green space system also has an aesthetic function, which can provide people with visual and aesthetic enjoyment, and bring people leisure and entertainment benefit.

(3) Ecological environment benefits include carbon fixation and oxygen release, biodiversity protection, soil conservancy and air purification. In the benefit of carbon fixation and oxygen release, green plants absorb $\mathrm{CO}_{2}$ from the atmosphere and release $\mathrm{O}_{2}$ into the air through photosynthesis, which not only provides fresh air, but also can effectively alleviate the greenhouse effect and maintain the dynamic balance of the atmosphere. Green plants providing humans with a suitable survival conditions, has 
an irreplaceable effect. In the benefit of biodiversity protection, urban green places have the function of biodiversity protection. Plants are closely linked to biodiversitygreen plants provide animals with material energy and habitat, as well as a place for information exchange between themselves and other organisms. In the benefit of soil conservancy, green areas can effectively reduce soil erosion, retain nutrients in the soil. The benefit of air purification in urban green spaces is mainly manifested in the reduction of harmful substances and the dust catching of woodlands. $\mathrm{SO}_{2}$ is the largest amount of harmful gas, and green plants absorb sulfides through the action of leaves to reduce its content in the air. Dust is an important pollutant that causes urban air pollution, but the dust catching effect of woodland can greatly improve air quality and reduce dust content.

The essence of urban reclaimed water greening benefit is the unity of economic benefit, social benefit, and ecological environment benefit, namely eco-economic benefit. (Fig 3)

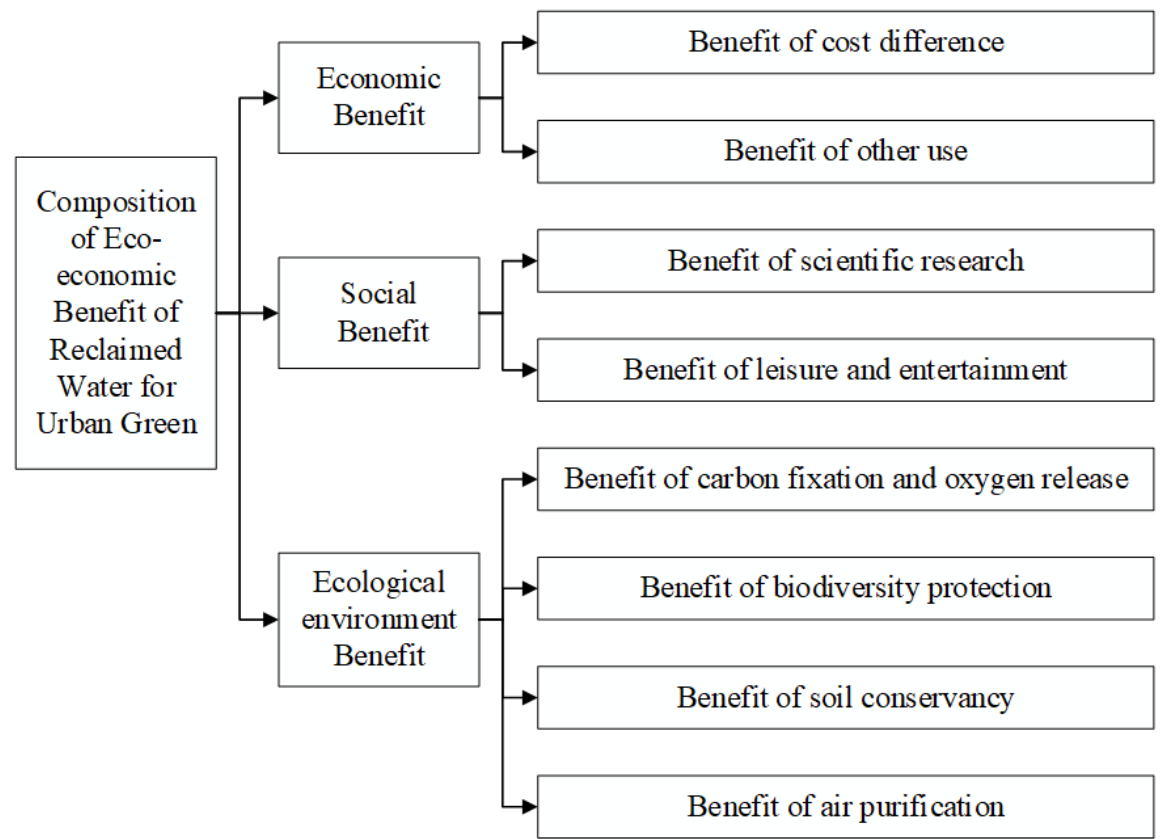


Fig3 Composition of Eco-economic benefit of reclaimed water for urban green

According to the methods of Odum (1996) and Lan et al (2002), the basic structure of the system and the situation of main energy, material, information and other ecological economic flow were analyzed, and the energy system diagram of ecological-economic system in urban green area was constructed (Fig. 4).

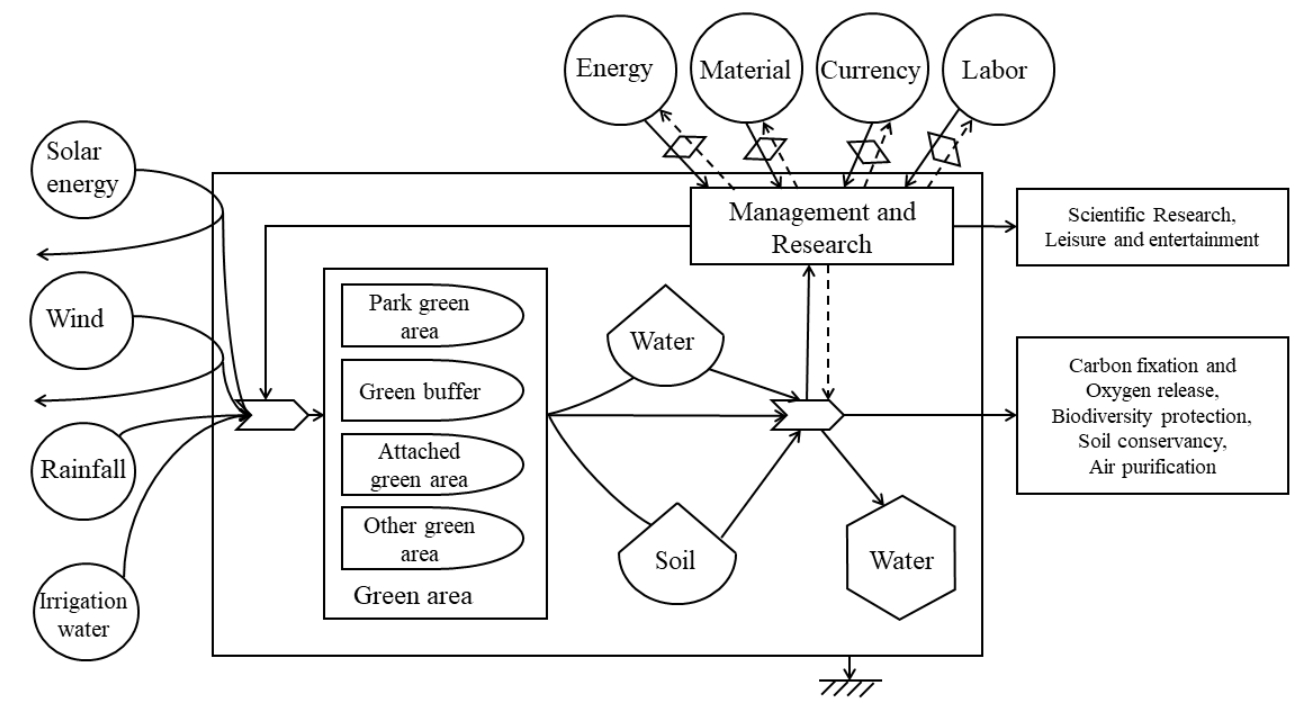

Fig4 Energy network diagram of urban green area eco-economic benefits

\subsection{Quantitative method of economic benefit of reclaimed water greening}

The economic benefit of reclaimed water greening is mainly divided into two parts, the former is the difference in cost of reclaimed water and tap water, the latter is the benefits of saving tap water for urban life or industrial production.

(1) The quantitative method of the benefit of cost difference

According to the emergy theory, water resources have various forms of energy input continuously in the natural and artificial circulation processes, which change the transformity of raw water ( $\operatorname{Lv} 2009)$. The transformity of different water bodies 
is the embodiment of their energy conversion, storage and consumption. It includes not only the value of raw water, but also the cost of transportation and treatment in the process of development and utilization of water resources. The transformity is the embodiment of water cost, so it can be used to calculate the cost value of green irrigation water. The formula is:

$$
E M_{C}=\left(\tau_{T W}-\tau_{R W}\right) W
$$

Where $E M_{C}$ is the difference between the cost emergy of water for urban greening (sej), $\tau_{T W}$ is the transformity of tap water ( $\operatorname{sej~} \mathrm{g}^{-1}$ ), $\tau_{R W}$ is the transformity of

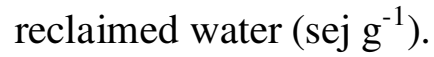

(2) The quantitative method of the benefit of saved tap water for other use

The calculation of other using benefit can be divided into the following two cases: one is tap water saved from reclaimed water greening entering the living system and generating living benefit. Another is tap water entering industrial system.

A) The quantitative method of the benefit of saved tap water into living system

The benefit of saved tap water into living system is mainly reflected in the recovery of labor force. The benefit of labor recovery mainly show that water resources maintain human life and health, they are measured by the contribution rate of water resources to maintaining normal labor value ( $\operatorname{Lv} 2009)$. The formula of benefit of saved tap water into living system is:

$$
E M_{A}=\frac{E M_{I N} \times W C R_{L} \times E}{W_{L}} \times W_{A}
$$

Where $E M_{A}$ is the total benefit of saved tap water into living system (sej), $E M_{I N}$ is the emergy of urban per capita disposable income (sej), $E$ is the local Engel 
co-efficient (\%), $W C R_{L}$ is the contribution rate of water resources to living system, which is annual per capita domestic water emergy divided by annual per capita total living input emergy (\%), the calculation method is according to $\operatorname{Lv}(2009), W_{L}$ is the annual per capita domestic water $\left(\mathrm{m}^{3}\right), W_{A}$ is the amount of saved tap water which entering the living system $\left(\mathrm{m}^{3}\right)$.

B) The quantitative method of the benefit of saved tap water into industrial system

The benefit of saved tap water into industrial system is mainly reflected in the output of industrial products. In the process of industrial production, water plays a complex role in the material and energy cycle of production system (Lv et al. 2020). The output of industrial products reflects the contribution of water as a factor of production in industrial economic activities, the formula is:

$$
E M_{B}=\frac{E M_{I Y} \times W C R_{I}}{W_{I}} \times W_{B}
$$

Where $E M_{B}$ is the total benefit of saved tap water into industrial system (sej), $E M_{I Y}$ is the total industrial capacity (sej), $W C R_{I}$ is the contribution rate of water resources to industrial system, which is water emergy for industrial production system divided by total industrial input emergy (\%), the calculation method is according to $\operatorname{Lv}(2009)$, $W_{I}$ is the quantity of water into industrial system $\left(\mathrm{m}^{3}\right), W_{B}$ is the amount of saved tap water which entering the industrial system $\left(\mathrm{m}^{3}\right)$.

\subsection{Quantitative method of social benefit of reclaimed water greening}

The social benefit of reclaimed water greening refers to the promotion of social 
development and the degree of psychological satisfaction to people from urban greening. It mainly included scientific research benefit, leisure and entertainment benefit.

(1) Benefit of scientific research

Referring to the method of Meillaud et al (2005) to calculate the scientific research benefit of reclaimed water. In the academic journal database, searching for academic papers in recent years with the keywords Zhengzhou, reclaimed water (intermediate water) and greening. And the emergy value of these academic papers is used as the scientific research service benefit of reclaimed water greening. The formula is:

$$
E M_{R}=P \times \tau_{R}
$$

Where $E M_{R}$ is the scientific research benefit (sej), $P$ is the total pages of academic papers published during the investigate period (page), $\tau_{R}$ is the transformity of Scientific Research (sej page ${ }^{-1}$ ).

(2) Benefit of leisure and entertainment

According to the study, the recreational value of urban green landscape is mainly related to the vegetation coverage area, this value is influenced by human preference. Xie's (Xie et al. 2003; Xie et al. 2015; Xie et al. 2015) equivalent factor method was used to calculate the leisure and entertainment benefit of reclaimed water greening. The formula is:

$$
E M_{E}=V \times S \times E D R
$$

Where $E M_{E}$ is the leisure and entertainment benefit of reclaimed water greening (sej), 
$V$ is the value equivalent of landscape leisure and entertainment services per unit of green area $\left(\$ \mathrm{~km}^{-2}\right)$, according to the value equivalent factor method proposed by Xie et al, $S$ is the greening coverage area of study region $\left(\mathrm{km}^{2}\right)$, Zhengzhou's greening coverage in 2018 is $250.65 \mathrm{~km}^{2}, E D R$ is the emergy currency ratio for Zhengzhou in $2018\left(\operatorname{sej} \$^{-1}\right)$.

\subsection{Quantitative method of ecological environment benefit of reclaimed water greening}

The purpose of urban greening is to improve the environment and beautify the city. The urban greening solves many environment problems, and brings lots of ecological environment benefits, such as the benefit of carbon fixation and oxygen release, biodiversity protection, soil conservation, and air purification.

(1) The quantitative method of the benefit of carbon fixation and oxygen release

The plants exchange materials with the atmosphere through photosynthesis and respiration, that is, fix $\mathrm{CO}_{2}$ and release $\mathrm{O}_{2}$. So as to maintain the balance of the atmosphere and providing oxygen essential for human survival. Therefore, the carbon fixation benefit of green area is calculated based on the annual carbon storage of plants, the release of $\mathrm{O}_{2}$ can be calculated from the chemical equation of photosynthesis. After calculating the annual amount of carbon fixation and oxygen release of green land, the corresponding emergy benefit can be obtained by multiplying the transformity. The formulas are:

$$
\begin{aligned}
& E M_{G}=S \times B \times \alpha \times \tau_{C_{2}} \\
& E M_{O}=S \times B \times \beta \times \tau_{O_{2}}
\end{aligned}
$$


Where $E M_{G}$ is the emergy of carbon fixation of urban green area (sej), $E M_{O}$ is the emergy of oxygen release of urban green area (sej), $S$ is local green coverage area $\left(\mathrm{km}^{2}\right), B$ is the biomass in unit area of deciduous broadleaved forest ( $\mathrm{Li}$ and Ren, 2004) $\left(\mathrm{t} \mathrm{km}^{-2} \mathrm{a}^{-1}\right), \alpha$ is the carbon fixation coefficient of per unit biomass, $\beta$ is the oxygen release coefficient of per unit biomass.

(2) The quantitative method of the benefit of biodiversity protection

With the expansion of the city scale and the enhancement of human activities, the original ecological environment has been changed. Green space is an important part of urban ecosystem, which can provide a variety of habitats and an important home for the reproduction of original organisms. The benefit of biodiversity protection can be expressed by the number of species and the area of biological activity in the region. The formula is:

$$
E M_{P}=\tau_{P} \times N \times R
$$

Where $N$ is the species number of the study area, $R$ is the proportion of biological activity area in this study to global area $(\%)$, the surface area of the earth is $5.1 \times 10^{8}$ $\mathrm{km}^{2}, \tau_{P}$ is the average solar emergy of per global specie (sej), it is calculated by the scholar Malmqvist (2003).

(3) The quantitative method of the benefit of soil conservation

Vegetation can effectively reduce soil erosion. On the one hand, the permeability of green space is strong, it is difficult to form surface runoff during precipitation, so the plants can reduce soil water erosion. On the other hand, vegetation protects against sand and wind, which can reduce soil wind erosion. The 
calculation of eco-economic benefit of urban green to fix soil, is based on the difference of latent soil erosion and practical soil erosion. According to the study of soil erosion in China, the modulus of soil practical erosion of temperate deciduous broadleaved forest is $550 \mathrm{t} \cdot \mathrm{km}^{-2} \cdot \mathrm{a}^{-1}$, the practical soil erosion in the green coverage area is only $5.1 \%$ of the latent soil erosion. The formula is:

$$
E M_{T}=\left(Q-Q^{\prime}\right) \times 678 \times \tau_{T}=(d \times S / 5.1 \%-d \times S) \times 678 \times \tau_{T}
$$

Where $E M_{T}$ is the emergy of annual soil conservation by green area (sej), $Q$ is the total amount of latent soil erosion (t), $Q^{\prime}$ is the total amount of practical soil erosion $(\mathrm{t}), d$ is modulus of soil practical erosion $\left(\mathrm{t} \mathrm{km}^{-2} \mathrm{a}^{-1}\right), S$ is local green coverage area $\left(\mathrm{km}^{2}\right), 678$ is the energy conversion ratio of plant surface soil $\left(\mathrm{J} \mathrm{g} \mathrm{g}^{-1}\right), \tau_{T}$ is the transformity of soil conservation (sej $\mathrm{J}^{-1}$ ).

(4) The quantitative method of the benefit of air purification

The benefit of air purification of urban green land can be reflected in the reduction of harmful substances produced by human society and dust catching function, which is mainly realized through the role of plant leaves. Due to the large leaf area of green plants, green land has strong absorption capacity for $\mathrm{SO}_{2}$, and have obvious filtration and adsorption effect on dust and soot. Therefore, the benefit of air purification by urban green land can be expressed by the absorption capacity of leaves to harmful substances and the green coverage area.

A) The benefit of green land to absorb $\mathrm{SO}_{2}$. According to the Research Report on the Situation of Biodiversity in China, the average capacity of deciduous broadleaved forest to absorb $\mathrm{SO}_{2}$ is $8865 \mathrm{~kg} \mathrm{~km}^{-2} \mathrm{a}^{-1}$. The formula is: 


$$
E M_{S}=q \times S \times \tau_{S}
$$

Where $E M_{S}$ is the emergy of green area to absorb $\mathrm{SO}_{2}$ (sej), $q$ is the average capacity of deciduous broadleaved forest to absorb $\mathrm{SO}_{2}\left(\mathrm{~kg} \mathrm{~km}^{-2} \mathrm{a}^{-1}\right), S$ is local green coverage area $\left(\mathrm{km}^{2}\right), \tau_{S}$ is the transformity of absorbing $\mathrm{SO}_{2}\left(\right.$ sej $\left.\mathrm{g}^{-1}\right)$.

B) The benefit of dust catching by green land. Broadleaved forest accounts for a large proportion in the study area, so the benefits of dust catching by green land could be generalized as the benefit of dust catching by broadleaved forest. The dust catching capacity of broadleaved forest is $3320 \mathrm{t} \mathrm{km}^{-2} \mathrm{a}^{-1}$. The formula is:

$$
E M_{K}=c \times S \times \tau_{K}
$$

Where $E M_{K}$ is the emergy of dust catching by broadleaved forest (sej), $c$ is the dust catching capacity of broadleaved forest $\left(\mathrm{t} \mathrm{km}^{-2} \mathrm{a}^{-1}\right), S$ is local green coverage area $\left(\mathrm{km}^{2}\right), \tau_{K}$ is the transformity of dust catching by broadleaved forest (sej $\mathrm{g}^{-1}$ ).

\section{Results and Discussion}

\subsection{Regional overview of the study}

Zhengzhou, the capital of Henan province, is located in the southern part of the North China Plain and the lower reaches of the Yellow River. Its total area is 7446.5 $\mathrm{km}^{2}$, urban area is $1010.3 \mathrm{~km}^{2}$ and built-up area is $543.9 \mathrm{~km}^{2}$. Zhengzhou belongs to the continental monsoon climate in the north temperate zone, with a warm temperate deciduous broadleaf forest vegetation type in the flora. And its urban greening rate is at the forefront of Chinese cities, with an urban greening coverage area of 250.65 $\mathrm{km}^{2}$, a built-up area greening coverage rate of $40.8 \%$, a green space rate of $35.8 \%$ and $14.3 \mathrm{~m}^{2}$ of public green space per capita. The specific city location profile and 
urban greening distribution is shown in Fig 5.

In terms of water resources, Zhengzhou is a severe water scarcity city. The multi-year average precipitation is $640.5 \mathrm{~mm}$. The per capita water capacity is only $179 \mathrm{~m}^{3}$, which is $1 / 40$ th of the global per capita water capacity. There are eight sewage treatment plants in Zhengzhou's main urban area, that basically achieved full collection and treatment of sewage, but the reuse rate of reclaimed water is low, only $17 \%$.

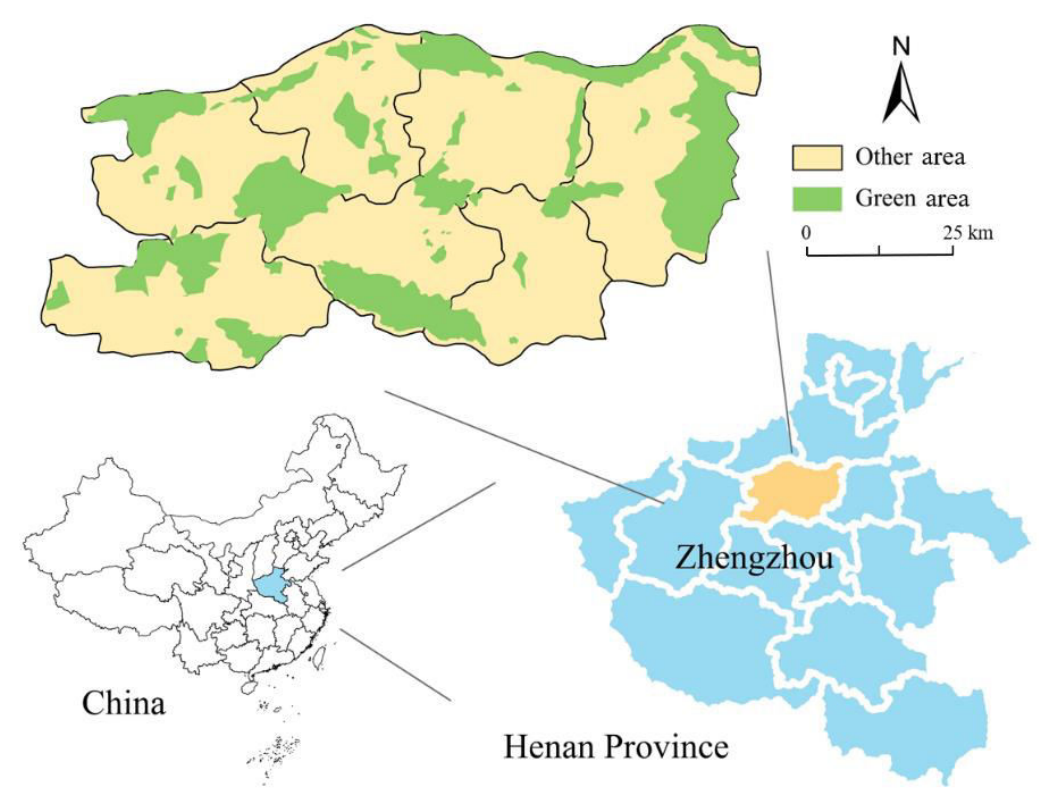

Fig5 Distribution of Green Area in Zhengzhou

At present, amounts of tap water is still used for green irrigation in Zhengzhou city. According to the above quantitative method, it was assumed that reclaimed water will be used to irrigate green land in Zhengzhou, and calculated the economic, social and ecological environment benefits. The social and economic data were obtained from the Zhengzhou Statistical Yearbook (ZSB 2019), and the water consumption data were obtained from the Zhengzhou Water Resources Bulletin 
(ZWRB 2018). The transformities were based on the research of Odum (1996) and Lan et al. (2002). The emergy currency ratio of Zhengzhou in 2018 was calculated according Lv' method (2009). Other data sources will be marked below.

\subsection{The quantification of economic benefit}

\subsubsection{The benefit of cost difference}

According to the current situation of green irrigation in Zhengzhou, the green coverage area needs irrigation was $250.65 \mathrm{~km}^{2}$ in 2018 . By the China's Standard for Design of Outdoor Water Supply (GB 50013-2018), the water quota for urban green land irrigation was $1.5 \mathrm{~L} \mathrm{~m}^{-2} \mathrm{~d}^{-1}$. It was calculated that the annual greening water consumption of Zhengzhou was $1.37 \times 10^{8}$ t. At present, there were 8 wastewater treatment plants in the main urban area of Zhengzhou, the total designed treatment capacity was 2.4 million $\mathrm{t} \mathrm{d}^{-1}$. The production of reclaimed water can fully satisfy the water consumption of green irrigation. The cost emergy of tap water and reclaimed water were calculated by formula (3), the cost emergy of tap water was $4.18 \times 10^{21}$ sej and the cost emergy of reclaimed water was $1.92 \times 10^{21}$ sej, the cost difference was $2.26 \times 10^{21}$ sej. The specific results were shown in Table 1 .

Table 1 Results of cost for urban green irrigation in Zhengzhou

\begin{tabular}{ccccc}
\hline Water source & Water consumption & Unit & Transformity (sej unit ${ }^{-1}$ ) & Emergy (sej) \\
\hline Tap water & $1.37 \times 10^{8}$ & $\mathrm{t}$ & $3.05 \times 10^{13}$ & $4.18 \times 10^{21}$ \\
Reclaimed water & $1.37 \times 10^{8}$ & $\mathrm{t}$ & $1.40 \times 10^{13}$ & $1.92 \times 10^{21}$ \\
\hline
\end{tabular}

Note: The transformity of tap water is from Lv (2009); the transformity of reclaimed water is from Lv (2020). 


\subsubsection{The benefit of saved tap water for other use}

The distribution data of saved tap water were calculated according to the Zhengzhou Water Resources Bulletin. In 2018, the proportion of industrial water and domestic water consumption in Zhengzhou was 78:100. According to this proportion, the amount of saved tap water would be allocated to 60 million $\mathrm{m}^{3}$ in industrial system and 77 million $\mathrm{m}^{3}$ in living system.

A) The benefit of saved tap water for living

By the above method, the calculation of water resources contribution rate to living system $\left(W C R_{L}\right)$ and the benefit of saved tap water for life $\left(E M_{A}\right)$ were calculated. The calculation of $W C R_{L}$ was shown in Table 2, the $E M_{A}$ was shown in Table 3.

Table 2 Contribution rate of water resources to life $\left(W C R_{L}\right)$ in Zhengzhou in 2018

\begin{tabular}{|c|c|c|c|c|}
\hline Emergy index & Basic data & Units & Transformity (sej unit ${ }^{-1}$ ) & Emergy (sej) \\
\hline 1 Per capita living emergy input & & & & $9.17 \times 10^{15}$ \\
\hline 1.1 Solar energy & $3.58 \times 10^{12}$ & $\mathrm{~J}$ & 1 & $3.58 \times 10^{12}$ \\
\hline 1.2 Wind energy & $6.20 \times 10^{9}$ & $\mathrm{~J}$ & $1.50 \times 10^{3}$ & $9.30 \times 10^{12}$ \\
\hline 1.3 Domestic water & 49.89 & $\mathrm{~m}^{3}$ & & $3.35 \times 10^{15}$ \\
\hline 1.3.1 Tap water & 34.59 & $\mathrm{~m}^{3}$ & $3.05 \times 10^{13}$ & $1.05 \times 10^{15}$ \\
\hline 1.3.2 Mineral water & 7.04 & $\mathrm{~m}^{3}$ & $1.43 \times 10^{14}$ & $1.01 \times 10^{15}$ \\
\hline 1.3.3 Pure water & 8.26 & $\mathrm{~m}^{3}$ & $1.56 \times 10^{14}$ & $1.29 \times 10^{15}$ \\
\hline 1.4 Life expenses & 26255.53 & $¥$ & $2.21 \times 10^{11}$ & $5.80 \times 10^{15}$ \\
\hline
\end{tabular}




\begin{tabular}{clll} 
Per capita disposable income & 39042.15 & $¥$ & $2.21 \times 10^{11}$ \\
\hline$W C R_{L}$ & $36.55 \%$ \\
\hline
\end{tabular}

Table 3 The benefit of saved tap water for life $\left(E M_{A}\right)$ in Zhengzhou in 2018

\begin{tabular}{|c|c|c|}
\hline Parameter & Units & Calculation results \\
\hline Contribution rate of water resources to life & $\%$ & 36.55 \\
\hline Engel co-efficient ${ }^{a}$ & $\%$ & 28 \\
\hline Per capita disposable income ${ }^{b}$ & $¥$ & 39042.15 \\
\hline Emergy benefit of per capita domestic water consumption & $10^{14} \mathrm{sej}$ & 8.83 \\
\hline Per capita domestic water consumption & $\mathrm{m}^{3}$ & 49.89 \\
\hline Emergy benefit of unit volume water & $10^{12} \mathrm{sej} / \mathrm{m}^{3}$ & 17.7 \\
\hline Saved tap water quantity into living system & $10^{8} \mathrm{t}$ & 0.77 \\
\hline$E M_{A}$ & $10^{21}$ sej & 1.36 \\
\hline
\end{tabular}

Note: $a$ and $b$ are from Zhengzhou Statistical Yearbook (ZSB 2019).

B) The benefit of saved tap water for industry

According to the quantitative method, the contribution rate of water resources to industrial system $\left(W C R_{I}\right)$ and the benefit of saved tap water for industry $\left(E M_{B}\right)$ were calculated. The $W C R_{I}$ was shown in Table 4, the $E M_{B}$ was shown in Table 5.

Table 4 Contribution rate of water resources to industry $\left(W C R_{I}\right)$ in Zhengzhou in 2018

\begin{tabular}{llccc}
\hline Emergy index & Basic data & Units & Transformity (sej unit ${ }^{-1}$ ) & Emergy (sej) \\
\hline 1 Emergy input & & $0.95 \times 10^{23}$ \\
\hline
\end{tabular}


1.1 Renewable environmental resources

1.1.1 Solar energy

1.1.2 Wind energy

1.1.3 Industrial water

1.1.3.1 Surface water

1.1.3.2 Groundwater

1.1.3.3 Tap water

1.2 Non-renewable environmental resources
$3.63 \times 10^{19}$

$6.29 \times 10^{16}$

$5.27 \times 10^{8}$

$2.87 \times 10^{8}$

$1.27 \times 10^{8}$

$1.13 \times 10^{8}$
$1.5 \times 10^{3}$

$9.43 \times 10^{19}$

$4.18 \times 10^{21}$

$1.85 \times 10^{12}$

$1.63 \times 10^{12}$

$2.07 \times 10^{20}$

$3.03 \times 10^{13}$

$3.44 \times 10^{21}$
1.2.1 Raw coal and coal products

1.2.2 Natural gas

1.2.3 Gasoline and other fuels

1.2.4 Electric power

1.2.5 Raw materia

1.2.6 Labor service

1.2.7 Depreciation of fixed assets
$7.22 \times 10^{17}$

$6.06 \times 10^{16}$

$2.62 \times 10^{15}$

$1.05 \times 10^{17}$

$1.07 \times 10^{11}$

$7.22 \times 10^{10}$

$¥$

$2.21 \times 10^{11}$

$1.60 \times 10^{22}$

$4.00 \times 10^{4}$

$2.89 \times 10^{22}$

$4.80 \times 10^{4}$

$2.91 \times 10^{21}$

$6.60 \times 10^{5}$

$1.73 \times 10^{21}$

$1.60 \times 10^{5}$

$1.68 \times 10^{22}$

$2.21 \times 10^{11}$

$2.37 \times 10^{22}$

2 Emergy output
$1.15 \times 10^{9}$

$¥$

$2.21 \times 10^{1}$

$1.93 \times 10^{23}$

2.1 Raw coal production

2.2 Thermal power generation

$1.48 \times 10^{17}$

$4.45 \times 10^{6}$
$1.89 \times 10^{6}$

$9.00 \times 10^{3}$

$5.52 \times 10^{4}$

$7.36 \times 10^{17}$

J

$1.56 \times 10^{5}$

$1.40 \times 10^{15}$

$1.60 \times 10^{16}$

$8.40 \times 10^{14}$

$3.80 \times 10^{15}$
$2.54 \times 10^{20}$

$2.94 \times 10^{22}$

$2.31 \times 10^{22}$

$2.56 \times 10^{21}$

$7.11 \times 10^{22}$

$7.56 \times 10^{18}$

2.6 Nitrogen fertilizer

$2.10 \times 10^{20}$ 


\begin{tabular}{|c|c|c|c|c|}
\hline 2.7 Phosphate fertilizer & $2.96 \times 10^{4}$ & $\mathrm{t}$ & $3.90 \times 10^{15}$ & $1.16 \times 10^{21}$ \\
\hline 2.8 Potassium fertilizer & $1.49 \times 10^{4}$ & $\mathrm{t}$ & $1.10 \times 10^{15}$ & $1.64 \times 10^{19}$ \\
\hline 2.9 Compound fertilizer & $9.70 \times 10^{4}$ & $\mathrm{t}$ & $2.80 \times 10^{15}$ & $2.72 \times 10^{20}$ \\
\hline 2.10 Pesticide & $3.13 \times 10^{3}$ & $\mathrm{t}$ & $1.60 \times 10^{15}$ & $5.00 \times 10^{18}$ \\
\hline 2.11 Plastic & $1.15 \times 10^{5}$ & $\mathrm{t}$ & $3.80 \times 10^{14}$ & $4.37 \times 10^{19}$ \\
\hline 2.12 Cement & $1.44 \times 10^{7}$ & $\mathrm{t}$ & $3.30 \times 10^{15}$ & $4.74 \times 10^{22}$ \\
\hline 2.13 Machine-made paper and paperboard & $7.91 \times 10^{5}$ & $\mathrm{t}$ & $3.90 \times 10^{15}$ & $3.09 \times 10^{21}$ \\
\hline 2.14 Chemicals and detergents & $1.51 \times 10^{4}$ & $\mathrm{t}$ & $1.00 \times 10^{15}$ & $1.51 \times 10^{19}$ \\
\hline 2.15 Food & $1.34 \times 10^{11}$ & $¥$ & $2.21 \times 10^{11}$ & $2.97 \times 10^{22}$ \\
\hline 2.16 Textile products & $2.49 \times 10^{10}$ & $¥$ & $2.21 \times 10^{11}$ & $5.51 \times 10^{21}$ \\
\hline 2.17 Wood production & $5.04 \times 10^{9}$ & $¥$ & $2.21 \times 10^{11}$ & $1.11 \times 10^{21}$ \\
\hline 2.18 Transportation equipment manufacturing & $1.20 \times 10^{11}$ & $¥$ & $2.21 \times 10^{11}$ & $2.65 \times 10^{22}$ \\
\hline
\end{tabular}

Table 5 The benefit of saved tap water for industry $\left(E M_{B}\right)$ in Zhengzhou in 2018

\begin{tabular}{ccc}
\hline Parameter & Units & Calculation results \\
\hline Total emergy of industrial water & $10^{21} \mathrm{sej}$ & \\
Total industrial input emergy & $10^{23} \mathrm{sej}$ & 0.95 \\
& & 1.93 \\
Total industrial output emergy & $10^{23} \mathrm{sej}$ & 4.42 \\
Contribution rate of water resources to industry & $(\%)$ & 8.55 \\
Emergy benefit of industrial water consumption & $10^{21} \mathrm{sej}$ & 5.27 \\
Industrial water consumption & $10^{8} \mathrm{~m}^{3}$ & 1.62 \\
\hline
\end{tabular}




\begin{tabular}{ccc}
\hline Saved tap water quantity into industrial system & $10^{8} \mathrm{t}$ & 0.60 \\
\hline$E M_{B}$ & $10^{21} \mathrm{sej}$ & 0.98 \\
\hline
\end{tabular}

Add the emergy benefit of saved tap water into living system and industrial system together, it was concluded that the other use benefit of reclaimed water greening in Zhengzhou city was $2.34 \times 10^{21}$ sej.

\subsection{The quantification of social benefit}

In the ScienceDirect full-text database (https://www.sciencedirect.com/), the Chinese General Knowledge Resources Database (https://www.cnki.net/) and the Chinese Science and Technology Journal Database (http://qikan.cqvip.com/), respectively used Zhengzhou, reclaimed water, and greening as keywords to search academic papers published during the six years from 2013 to 2018. The results of a total of 59 articles, an average of 10 articles per year, an average of 6 pages per article calculated, a total of 60 pages. The original data of scientific research benefit were obtained, and the emergy benefit of scientific research was calculated by formula (6). The original data of leisure entertainment benefit were obtained by the equivalent factor method, and the emergy benefit was calculated by formula (7). The calculation results were shown in Table 6.

Table 6 The social benefit of reclaimed water greening in Zhengzhou in 2018

\begin{tabular}{ccccc}
\hline Classification of specific benefit & Basic data & Units & Transformity (sej unit ${ }^{-1}$ ) & Emergy (sej) \\
\hline Scientific research $^{c}$ & 60 & page & $3.39 \times 10^{15}$ & $2.03 \times 10^{17}$ \\
Leisure and entertainment ${ }^{d}$ & $1.40 \times 10^{7}$ & $\$$ & $1.60 \times 10^{12}$ & $2.05 \times 10^{19}$ \\
\hline Total & & & $2.07 \times 10^{19}$ \\
\hline
\end{tabular}


Note: the transformity of $c$ referenced Meillaud (2005), the transformity of $d$ is calculated by this study.

\subsection{The quantification of ecological environment benefit}

Based on the above methods to calculate the carbon fixation and oxygen release, biodiversity conservation, soil sequestration and air purification benefit of reclaimed water greening. The number of species in Zhengzhou's green areas was 314, and the emergy benefit of protecting biodiversity was calculated by equation (10). The emergy benefits of carbon fixation and oxygen release, soil sequestration and air purification were calculated by equation (11), equation (12) and equation (13) respectively. The results of the calculations were shown in Table7.

Table 7 The environment benefit of reclaimed water greening in Zhengzhou in 2018

\begin{tabular}{|c|c|c|c|c|}
\hline Classification of specific benefit & Basic data & Units & Transformity (sej unit ${ }^{-1}$ ) & Emergy (sej) \\
\hline Carbon fixation and Oxygen release ${ }^{e}$ & & & & $3.07 \times 10^{20}$ \\
\hline $\mathrm{CO}_{2}$ fixation & $4.09 \times 10^{12}$ & $\mathrm{~g}$ & $3.78 \times 10^{7}$ & $1.55 \times 10^{20}$ \\
\hline Release $\mathrm{O}_{2}$ & $2.98 \times 10^{12}$ & $\mathrm{~g}$ & $5.11 \times 10^{7}$ & $1.52 \times 10^{20}$ \\
\hline Biodiversity protection & & & & $1.91 \times 10^{21}$ \\
\hline Soil conservancy ${ }^{f}$ & $1.74 \times 10^{15}$ & $\mathrm{~J}$ & $7.40 \times 10^{4}$ & $1.29 \times 10^{20}$ \\
\hline Air purification ${ }^{g}$ & & & & $1.25 \times 10^{20}$ \\
\hline Absorption of $\mathrm{SO}_{2}$ & $2.22 \times 10^{9}$ & $\mathrm{~g}$ & $6.66 \times 10^{7}$ & $1.48 \times 10^{17}$ \\
\hline Dust catching & $8.32 \times 10^{11}$ & $\mathrm{~g}$ & $1.50 \times 10^{8}$ & $1.25 \times 10^{20}$ \\
\hline Total & & & & $2.47 \times 10^{21}$ \\
\hline
\end{tabular}

Note: the transformity of $e, f, g$ referenced Sun (2008). 


\subsection{Results and analysis}

According to the above calculation results, the total eco-economic benefit of reclaimed water and tap water greening could be get, and also the net benefit after deducting the cost. By dividing the emergy benefit to the local emergy currency ratio in the current year (After calculation, the emergy currency ratio of Zhengzhou in 2018 was $\left.1.46 \times 10^{12} \mathrm{sej} / \$\right)$, could obtained the corresponding monetary benefit, the results were shown in Table 8 .

Table 8 Summary of eco-economic benefit of reclaimed water greening in Zhengzhou in 2018

\begin{tabular}{|c|c|c|c|}
\hline Types & Classification of specific benefit & Emergy benefit (sej) & Monetary benefit (\$) \\
\hline & Cost difference $\left(E M_{C}\right)$ & $2.26 \times 10^{21}$ & $1.55 \times 10^{9}$ \\
\hline \multicolumn{4}{|l|}{ Economic } \\
\hline & Saved tap water into living system $\left(E M_{A}\right)$ & $1.36 \times 10^{21}$ & $9.32 \times 10^{8}$ \\
\hline \multicolumn{4}{|l|}{ benefit } \\
\hline & Saved tap water into industrial system $\left(E M_{B}\right)$ & $9.80 \times 10^{20}$ & $6.71 \times 10^{8}$ \\
\hline Social & Scientific research $\left(E M_{R}\right)$ & $2.03 \times 10^{17}$ & $1.39 \times 10^{5}$ \\
\hline \multirow[t]{3}{*}{ benefit } & Leisure and entertainment $\left(E M_{E}\right)$ & $2.05 \times 10^{19}$ & $1.40 \times 10^{7}$ \\
\hline & Carbon fixation $\left(E M_{G}\right)$ & $1.55 \times 10^{20}$ & $1.06 \times 10^{8}$ \\
\hline & Oxygen release $\left(E M_{O}\right)$ & $1.52 \times 10^{20}$ & $1.04 \times 10^{8}$ \\
\hline \multicolumn{4}{|l|}{ Ecological } \\
\hline & Biodiversity protection $\left(E M_{P}\right)$ & $1.91 \times 10^{21}$ & $1.31 \times 10^{9}$ \\
\hline & Soil conservancy $\left(E M_{T}\right)$ & $1.29 \times 10^{20}$ & $8.82 \times 10^{7}$ \\
\hline & Absorption of $\mathrm{SO}_{2}\left(E M_{S}\right)$ & $1.48 \times 10^{17}$ & $1.01 \times 10^{5}$ \\
\hline & Dust catching $\left(E M_{K}\right)$ & $1.25 \times 10^{20}$ & $8.56 \times 10^{7}$ \\
\hline Total benefit & Reclaimed water & $7.09 \times 10^{21}$ & $4.86 \times 10^{9}$ \\
\hline
\end{tabular}




\begin{tabular}{|c|c|c|c|}
\hline & Tap water & $2.49 \times 10^{21}$ & $1.71 \times 10^{9}$ \\
\hline \multirow{3}{*}{ Net benefit } & Reclaimed water & $2.91 \times 10^{21}$ & $2.00 \times 10^{9}$ \\
\hline & & & \\
\hline & Tap water & $-1.69 \times 10^{21}$ & $-1.16 \times 10^{9}$ \\
\hline
\end{tabular}

(1) The total eco-economic benefit of reclaimed water for urban green in Zhengzhou in 2018 was $7.09 \times 10^{21}$ sej and the monetary benefit was $\$ 4.86$ billion. The benefit of reclaimed water greening was three times of the tap water. The net eco-economic benefit of reclaimed water greening was $2.91 \times 10^{21}$ sej, the monetary benefit was $\$ 2.00$ billion. But the net benefit of tap water greening was negative, it showed that tap water greening was not only unable to obtain certain economic value, but also caused economic losses. The total benefit and net benefit of tap water and reclaimed water were show in Fig 6. Maestre-Valero et al. (2016) set up tap water, reclaimed water, $R D I$ treatment tap water, $R D I$ treatment reclaimed water 4 groups of experiments to irrigate grapefruit, determined profitability of different irrigation experiments. It was concluded that reclaimed water irrigation was the most profitable irrigation strategy, also proved that in the case of water shortage, reclaimed water was a better choice. 


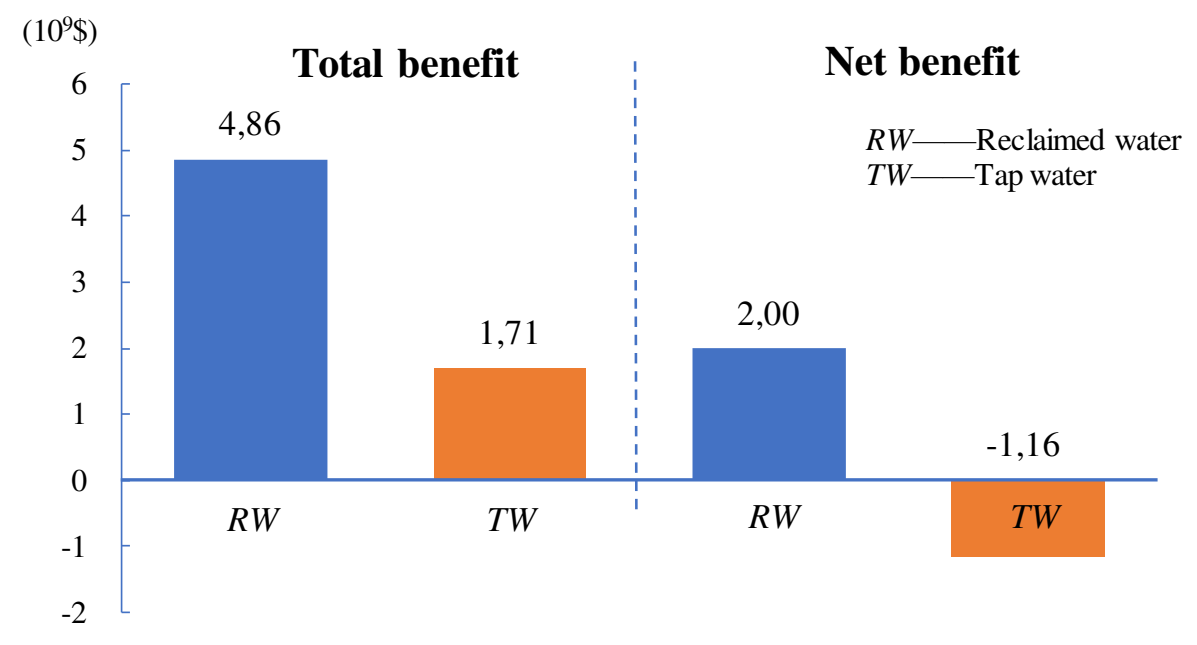

Fig6 Total and net eco-economic benefit of reclaimed water and tap water greening

(2) Among the total eco-economic benefit of reclaimed water greening, the economic benefit accounted for $64.87 \%$, the social benefit accounted for $0.29 \%$, the ecological environment benefit accounted for $34.84 \%$. The composition of economic benefit was precisely because the green water source was replaced by reclaimed water, resulting in the cost difference benefit and other using benefit by saved tap water. It can be seen that the economic benefit of reclaimed water greening was very significant. The proportion of eco-economic benefit of reclaimed water greening was shown in Fig 7. 


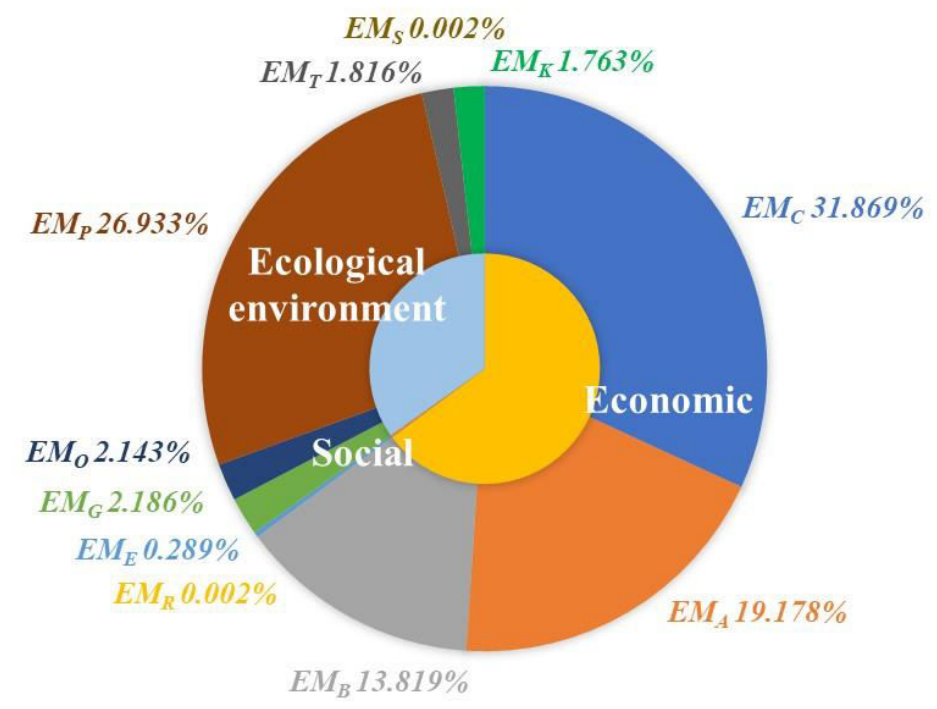

Fig7 Proportional of eco-economic benefit of reclaimed water greening

(3) Among the economic benefit of reclaimed water greening: the cost emergy of tap water and reclaimed water was $1.92 \times 10^{21}$ sej and $4.18 \times 10^{21}$ sej, the monetary benefit was $\$ 1.55$ billion and $\$ 2.86$ billion. The cost of reclaimed water green irrigation was $46 \%$ of that of tap water, the monetary benefit of the cost difference was $\$ 1.55$ billion, it greatly saved the cost of urban greening. Pardo et al. (2020) considered the civil work of wastewater treatment plant, piped irrigation network, land, asphalt, electrical devices, indirect costs, taxes and so on when they were calculating the cost of reclaimed water. At last, they obtained the cost of reclaimed water was $60 \%$ of the local tap water price, it was also concluded that the cost of reclaimed water was lower than that of tap water. The benefit of saved tap water for other use was $2.34 \times 10^{21}$ sej, the monetary benefit was $\$ 1.60$ billion, it was the most beneficial item in all projects, accounting for $32.9 \%$ of the total benefit. The economic benefit which the optimal utilization of saved tap water had brought 
can't be ignored.

\section{Conclusions}

Reclaimed water reuse is an effective way to solve the shortage of water resources and improve the utilization efficiency of water resources. Reclaimed water for urban greening irrigation has great benefits in economy, society and ecological environment. The quantitative analysis of these benefits was still in the exploration stage, lacking to consider comprehensively the quantitation of eco-economic benefit of reclaimed water reuse. Based on emergy theory in this paper, combining ecology and economics, the eco-economic benefit of reclaimed water greening was fully analyzed and a new quantitative analysis method was put forward. In the case calculation of Zhengzhou in 2018, the economic, social and ecological benefits of urban green irrigation by using reclaimed water were quantitatively analyzed. The results showed that, reclaimed water greening can not only achieve the same social and ecological environmental benefits as tap water, but also greatly save the cost. The use of reclaimed water can save a lot of tap water, which was put into industrial production and living system would bring huge economic benefit, the value of quality tap water can be fully applied. The scientific and comprehensive quantification method is helpful to the rational distribution and utilization of reclaimed water, and it is also helpful to its reuse. There are still some shortcomings in this paper. Because of the complex analysis and difficult calculation of the transformity, most of the transformities were referred to the previous results. The calculation of the transformity calculation of greening benefits is still needed further 
research.

Ethical Approval Informed consent.

Consent to Participate Informed consent.

Consent to Publish Informed consent.

Authors Contributions Conceptualization: Cuimei Lv; Methodology: Cuimei Lv and Yifan He; Formal analysis and investigation:Yifan $\mathrm{He}$ and Wenge Zhang; Writing - original draft preparation: Cuimei Lv, Yifan He and Wenge Zhang; Writing - review and editing: Cuimei Lv, Yifan He, Changkuan Gu and Denghua Yan; Resources: Denghua Yan; Supervision: Yang Li.

Funding This research was funded by the National Natural Science Foundation of China (No. NSCF-52079125 and No. NSCF-51909240).

Availability of data and materials All data and materials support our published claims and comply with field standards.

\section{Conflict of Interest None.}

\section{Reference}

Alcon F, Martin-Ortega J, Berbel J, de Miguel M D (2012). Environmental benefits of reclaimed water: an economic assessment in the context of the Water Framework Directive. Water Policy, 14(1):148. Doi: https://doi.org/10.2166/wp.2011.001. 
Alcon F, Martin-Ortega J, Pedrero F. (2013). Incorporating non-market benefits of reclaimed water into cost-benefit analysis: a case study of irrigated mandarin crops in southern Spain. Water Resources Management, 27(6), 1809-1820. Doi: https://doi.org/10.1007/s11269-012-0108-z.

Birol E, Koundouri P, Kountouris Y. (2010). Assessing the economic viability of alternative water resources in water-scarce regions: combining economic valuation, cost-benefit analysis and discounting. Ecological Economics, 69\{A), 839-847. Doi: https://doi.org/10.1016/j.ecolecon.2009.10.008.

Brown M T, Ulgiati S. (2004). Energy quality, emergy, and transformity: H.T. Odum' s contribution to quantifying and understanding systems. Ecological Modelling, (178):201-213. Doi: https://doi.org/10.1016/j.ecolmodel.2004.03.002.

Chen Y, Gan X. (2014). A Comprehensive Benefit Analysis of Reuse of Urban Recycled Water: Taking Recycled Water Reuse Project of Chongqing Longtousi Park for Example. China Municipal Engineering, (05):44-46+114.

Cirelli G L, Consoli S, Grande V D, Milani M, Toscano A. (2007). Subsurface constructed wetlands for wastewater treatment and reuse in agriculture: five years of experiences in sicily, Italy. Water Science \& Technology A Journal of the International Association on Water Pollution Research, 56(3), 183-91. Doi: https://doi.org/10.2166/wst.2007.498.

Galvis A, Jaramillo M F, Van d S P, Gijzen H J. (2018). Financial aspects of reclaimed wastewater irrigation in three sugarcane production areas in the Upper Cauca River Basin, Colombia. Agricultural Water Management, 
209:102-110. Doi: https://doi.org/10.1016/j.agwat.2018.07.019.

Garcia X, Pargament D. (2015). Pargament. Reusing wastewater to cope with water scarcity: Economic, social and environmental considerations for decision-making. Resources, Conservation \&amp; Recycling, 101:154-166. Doi: https://doi.org/10.1016/j.resconrec.2015.05.015.

Giannoccaro G, Arborea S, Gennaro B, Iacobellis V, Piccinni A. (2019). Assessing Reclaimed Urban Wastewater for Reuse in Agriculture: Technical and Economic Concerns for Mediterranean Regions. Water, 11(7):1511. Doi: https://doi.org/10.3390/w11071511.

Pérez-Pérez J G, García J, Robles J M, Botía P. (2010). Economic analysis of navel orange cv. 'Lane late' grown on two different drought-tolerant rootstocks under deficit irrigation in South-eastern Spain. Agricultural Water Management, 97(1):157-164. Doi: https://doi.org/10.1016/j.agwat.2009.08.023.

Pérez-Pérez J G, Robles J M, Botía P. (2014). Effects of deficit irrigation in different fruit growth stages on 'star ruby' grapefruit trees in semi-arid conditions. Agricultural Water Management, 133(C), 44-54. Doi: https://doi.org/10.1016/j.agwat.2013.11.002.

Lan S, Qin P, Lu H. (2002). Emergy Analysis of Ecological Economic System. Beijing: Chemical Industry Press.

Li G, Ren H. (2004). Biomass and Net Primary Productivity of The Forests in Different Climatic Zones of China. Tropical Geography, (04):306-310. Doi: 10.3969/j.issn.1001-5221.2004.04.002. 
Li H. (2017). Study on Model of Environmental Cost-Benefit Analysis on Reclaimed Water Reuse in Residential Communities. China University of Mining and Technology.

Lv C, Ling M, Wu Z, Guo X, Cao Q. (2019). Quantitative assessment of ecological compensation for groundwater overexploitation based on emergy theory. Environmental Geochemistry and Health. Doi: https://doi.org/10.1007/s10653-019-00248-z.

Lv C, Zhang W, Ling M, Li H, Zhang G. (2020). Quantitative analysis of eco-economic benefits of reclaimed water for controlling urban dust. Environmental Geochemistry Health. Doi: https://doi.org/10.1007/s10653-020-00537-y.

Lv C. (2009). Research on Ecological Economic Value of Regional Water Resources Based on Emergy Theory. Zhengzhou University.

Maestre-Valero J F, Martin-Gorriz B, Alarcón J J, Nicolas E, Martinez-Alvarez, V. (2016). Economic feasibility of implementing regulated deficit irrigation with reclaimed water in a grapefruit orchard. Agricultural Water Management, 178:119-125. Doi: https://doi.org/10.1016/j.agwat.2016.09.019.

Malmqvist J B. (2003). Mechanisms behind positive diversity effects on ecosystem functioning: testing the facilitation and interference hypotheses. Oecologia, 134(4), 554-559. Doi: https://doi.org/10.1007/s00442-002-1148-5.

Meillaud F, Gay J B, Brown M T. (2005). Evaluation of a building using the emergy method. Solar Energy, $79(2): 204-212$. Doi: 
https://doi.org/10.1016/j.solener.2004.11.003.

ODUM H T. (1996). Environmental accounting: emergy and decision making. New York: Wiley.

Pardo M A, ángela pérez montes, Moya-Llamas, M. J. (2021). Using reclaimed water in dual pressurized water distribution networks. cost analysis. Journal of Water Process Engineering. Doi: https://doi.org/10.1016/j.jwpe.2020.101766.

Sun J. (2008). Evaluation of Ecosystem Service Value of Wuyishan Nature Reserve based on the Emergy Analysis. Fujian Agriculture and Forestry University.

Tsagarakis K P. (2005). Recycled water valuation as a corollary of the 2000/60/EC water framework directive. Agricultural Water Management, 72(1), 1-14. Doi: https://doi.org/10.1016/j.agwat.2004.09.006.

Wang Q, Shi C, Liu Y, Zhou D, Sun J. (2012). Study on Health Risk Assessment of Reclaimed Water Used of Greenbelt Irrigation. Water Saving Irrigation, (03):57-60.

Wang Q. (2010). Effect of Reclaimed Water Irrigation on Urban Greenbelt Ecological System and Safety Evaluation. Gansu Agricultural University.

Wu Z, Guo X, Lv C, Wang H, Di D. (2017). Study on the quantification method of water pollution ecological compensation standard based on emergy theory. Ecological Indicators, $\quad$ S1470160X17306209. Doi: https://doi.org/10.1016/j.ecolind.2017.09.052.

Xie G, Lu C, Leng R, Zhang D, Li S. (2003). Ecological Assets Valuation of the Tibetan Plateau. Journal of Natural Resources, (02):189-196. Doi: 
10.11849/zrzyxb.2003.02.010

Xie G, Zhang CX, Zhang CS, Xiao Y, Lu C. (2015). The Value of Ecosystem Services in China. Resources Science, 37(09):1740-1746. Doi:

Xie G, Zhang C, Zhang L, Chen W, Li S. (2015). Improvement of the Evaluation Method for Ecosystem Service Value Based on Per Unit Area. Journal of Natural Resources, 30(08):1243-1254. Doi:10.11849/zrzyxb.2015.08.001

Zhengzhou statistical yearbook (2019), Zhengzhou Statistics Bureau (ZSB), Zhengzhou, Henan Province, China.

Zhengzhou water resources bulletin (2018), Zhengzhou Water Conservancy Bureau (ZWCB), Zhengzhou, Henan Province, China. 